\title{
The Morphosyntactic Interface of Determiner Phrases
}

\author{
Gabrielle Klassen ${ }^{1}$, John W. Schwieter ${ }^{2}$ \\ ${ }^{1}$ Department of Spanish and Portuguese, University of Toronto, Toronto, Canada \\ ${ }^{2}$ Department of Languages and Literatures, Wilfrid Laurier University, Waterloo, Canada \\ Email: gabrielle.klassen@mail.utoronto.ca
}

Received July $10^{\text {th }}, 2013$; revised August $9^{\text {th }}, 2013$; accepted August $17^{\text {th }}, 2013$

\begin{abstract}
Copyright (C) 2013 Gabrielle Klassen, John W. Schwieter. This is an open access article distributed under the Creative Commons Attribution License, which permits unrestricted use, distribution, and reproduction in any medium, provided the original work is properly cited.
\end{abstract}

\begin{abstract}
The functional category of determiners has undergone a number of representational changes in the last half century. Beginning with Abney in 1987 and as early as work by Brame $(1981,1982)$ and Postal (1966), linguists began to adapt the notion that determiners were a type of functional category with phrasal structure, and not specifiers of noun phrases. The flexibility allotted to this category to hold a significant role in syntactic structure has led to theories of feature and feature strength and the development of these features in first and second language acquisition. This paper seeks to review the current theories of syntactic structure of determiner phrases in English and universally. In particular, it examines one area of controversy regarding this category, namely nominal gender agreement, and how this affects applied areas of linguistics. Recent studies seem to favor specific transfer theories, however the default hypothesis that arises leaves much to be considered. From the discussion, we argue that gender feature agreement in L1 and L2 acquisition is distinct and merits further investigation, perhaps benefiting from the recent developments in the area of psycholinguistics.
\end{abstract}

Keywords: Morphosyntax; Determiner Phrases; Transfer Theories; Gender Agreement

\section{Introduction}

Contrasting theories in the area of the syntactic functional category of determiner phrases (DPs) continues to be a controversial area of theoretical linguistics. Following work done by Abney (1987), or as Chomsky (1995) argues as early as works by Brame (1981, 1982) and Postal (1966), linguists have begun to adapt the theory that determiners are a type of functional category with phrasal structure, and not specifiers of noun phrases. This train of thought has led to an entirely new interpretation of determiners and the implications that this has on syntactic theory are just beginning to be investigated. This paper seeks to review such theories, universal features, and feature options, and to provide an overview of the English DP parameters, and some cross-linguistic variability (using Spanish as one particular example). It will then focus on nominal gender agreement and the issues that arise in other areas of applied linguistics, such as first (L1) and second language (L2) acquisition, and psycholinguistics, as an illustration of the importance and far-reaching implications of this area of syntactic theory. The latter section will examine two key areas of debate concerning gender agreement; transfer theories (Epstein, Flynn, \& Martohardjono, 1996; Schwartz \& Sprouse, 1996; White, 1985; Prévost \& White, 2000), and the Default Hypothesis (Bruhn de Garavito \& White, 2002). This overview of current theories and conflicts, as well as some suggested solutions, is intended to spark future research in this area and to add clarity and cohesion to the studies recently put forth.

\section{Syntactic Category: Determiners in English}

Beginning with an overview of how to interpret a determiner syntactically, it is important to define what is meant by "determiner". Besides the traditionally thought of articles the and a, several other very similar types of words can be represented in the same syntactic position (i.e., directly preceding nouns). These include personal pronouns (my, his, her etc.), demonstratives (this, that), and numerals. There is, therefore, a dissociation between determiners and the position that they typically occupy. The functional category of determiners will contain a variety of word classes, including determiners, demonstratives, possessive pronouns, among others. In this paper, we will use determiner to refer to the syntactic category, including the above mentioned word classes as well.

The determiner position also has several binary feature options. However, these features may not always be lexically associated with a particular word. Korzen (2008) argues that the most inherent feature of any determiner is [+/- identifiable] which marks specificity. It has also come to be known as [+/definite], a feature that is often falsely automatically associated with all determiners. Korzen considers the relationship between definite and specificity features in Italian, among other areas. Since words typically have features associated with them in the lexicon, there is now the option that these features are assigned syntactically by the position itself and have no necessary relationship to the meaning of the word. They are then in theory produced in Surface Structure and "spelled-out" at the Phonetic Form (PF) interface with the presence (or absence) of a word (Chomsky, 1995).

If determiners, then, are merely a collection of features, then universally we would expect to find the same features, or at least feature options, across languages. In other words, we 
would expect determiners to have matching equivalents across languages to function in the same necessary ways. These features play a significant role in syntactic structure and semantic interpretation:

Within the minimalist program it is assumed that syntactic operations are essentially feature driven: features are standardly assumed to undergo and thus trigger movement and/or agreement (Wiltschko, 2009: p. 64).

We will consider in further detail later on some of these possible features. With a basic understanding of what a determiner is, we must first consider how to syntactically represent this information. The traditional view of the relationship of determiners and nouns seems similar to that of degree words and adjectives, or that of qualifiers and verbs. This would indicate a specifier-head relationship. However, it is generally accepted in modern syntactic analysis that the relationship of determiners to noun phrases is more like that of I (inflection) to verb phrases. It is the head of the noun phrase, and dominates it syntactically ${ }^{1}$. There is now the issue of how to represent the DP. We will adopt Abney's (1987) theory, and so the DP will have a complement NP instead of being the specifier of the NP.

From a minimalist point of view, these DPs must exist only as long as they serve a vital purpose (referring to the concept of economy, or the use of putting forth the minimal effort possible). They will, therefore, have a D' level, to accommodate a noun phrase that they will dominate and a D head level, for a possible overt determiner. The first potential problem that arises with this theory is that determiners are not always overtly present. In many cases, they can be left out. Consider the following sentence taken from Zamparelli (2008):

(1) He sees dogs in the street.

The dogs are non-specific, and therefore do not require a determiner to mark [ + identifiable]. However, it is syntactically plausible for one to exist, changing the meaning of dogs to be $a$ specific set of dogs. From a minimalist point of view, it would at first glance seem acceptable to eliminate the DP in this case, if specificity is always marked by an overt determiner. However, there are other factors to consider before one can eliminate the DP altogether. We have already established that determiners and the D position do not always go hand in hand in everyday understanding, as other categories often fall under this position as well, such as these, my, some. If the DP has the same relationship as an inflective phrase (IP) does with a verb phrase (VP), then we can assume that DPs would also contain other features that may or may not be overtly expressed (e.g., the IP marks [+/- past], and cannot simply be removed if an auxiliary is not present). This implies that there must be more features to be checked under D than just those which may be checked by the presence of the.

Similar assumptions have lead researchers to propose an empty (null) category for the D position when a determiner is not overtly present (Longobardi, 2008). This is not an unfamiliar concept, given that the empty category PRO has been proposed to represent a non-specific pronoun in infinitive phrases in the [Spec, IP] position, and an operator (Op) to represent the direct object under $\mathrm{C}$ in a complement phrase in which the direct object is overtly lacking (Chomsky, 1995). Both of these are required to check the features of their respected categories. Minimalist considerations would argue that this is a plausible hypothesis. Where there is no overt determiner, such as in (1),

${ }^{1}$ We refer here to the syntactic DP category, not to the strictly lexicallydefined determiners. an empty category will hold its place.

By this logic, there is an assumed DP as the head of every noun phrase, leaving the potential for a determiner to exist, and checking the necessary features for proper interpretation. This also accommodates the internal projection of functional categories of DP. Numbers, although not strictly determiners in the lexical sense, have been proposed to occupy an internal projection or functional category number phrase (NumP), and the indefinite determiner $a$ will also occupy this position, since it originally began as a singular marker (and always refers to only one) (Muller \& Klinge, 2008). Now that there is a null category under the D head, the phrase is safe from having two determiners, thus making it safe from becoming ungrammatical in English. Other functional words that precede nouns may fall under $\mathrm{D}$, such as demonstratives (this, those), whereas others with more distinct features, like possessive pronouns (my, your, his), will also have their own internal projection or functional category to occupy (Demonstratives being determiners that contain the feature [+/- location]: Wiltschko, 2009). Cowper and Currie Hall (2009) argue that there indeed is a difference between [specific] and [definite], previously assumed to be the same. Gillon (2009) argues that anything that occurs under D position makes the phrase [+ definite] only when combined with a [+ unique] feature, but Cowper and Currie Hall modify this slightly by positing that the $\mathrm{D}$ position being occupied will "introduce a choice function" and it will only acquire the [+ definite] feature from the addition of other features (p. 101).

Another syntactic structure peculiarity to consider in English is that of the genitive 's. Although not all languages face this complication in their morphology, the genitive 's occurs in complementary distribution with determiners. Take for example the following sentences:

(2) The woman's book.

(3) The book of the woman.

(4) *The woman's the book.

(5) Her book.

As demonstrated by the ungrammatical nature of (4), the genitive 's marks the same syntactic features as the preposition and determiner in (3). This would suggest that in a sentence like (2), the ' $s$ is the determiner head dominating the rest of the phrase, leaving [DP The woman] as the specifier of [DP 's [NPbook]] (Carnie, 2002). Also consider sentence (5), showing possession to be a determiner (or as mentioned above, at least an internal projection of a determiner). Since 's also marks possession, it makes sense to treat it in the same manner.

So far we have established a basis for syntactically representing determiners in English, using a minimalist framework and various features. We have included only what is necessary for convergence at the Logical (interpreted) Form (LF). The necessary features will vary according to the type of noun it precedes. For example, Massam and Ghomeshi (2009) argue that the null category preceding proper nouns will include [proper], [singular], and [definite]. This is merely a list of possible options for determiners specific to English.

\section{Bare Nouns}

We begin our cross-linguistic analysis of English and other languages in their treatment of bare nominals (nouns that never occur with overt determiners). For example, proper names like James do not typically occur with a determiner when referring to a specific person (e.g., *The James). In other languages, like 
Italian, this is not the case. In Italian proper names can occur after both an overt determiner and a possessive pronoun in the same phrase, or before a possessive pronoun or even on its own. Consider the following phrases in Italian:

(6) La mia Maria. Lit.: The-(Det.) my Maria

(7) Maria mia. Lit.: Maria my.

(8) *Mia Maria. Lit.: My Maria.

Using similar phrases, Longobardi (1994) argues that proper names appear to raise to the D position, to check features of definiteness or specificity, and leave a trace if an overt determiner is not already present. This explains the grammaticality of (7) and the ungrammaticality of (8).

Longobardi (2008) provides another interesting example with the treatment of adjective phrase modifiers and noun phrases. Consider the following examples of nouns in subject position ( $\mathrm{p}$. 191):

(9) L'antica Roma.

Lit.: Det.-The ancient Rome.

(10) *Antica Roma.

Lit.: Ancient Rome.

(11) Roma Antica.

Lit.: Rome Ancient.

Here again the only acceptable word order in English is the only unacceptable word order in Italian. It seems reasonable to posit that the raising of proper nouns to D position is possible in Italian but not in English.

Massam and Ghomeshi (2009) provide evidence that "[...] proper names can appear with determiners or their functional equivalents" (p. 70). Here again, there is evidence that proper names may be treated differently in other languages. The proposed difference here is the distinction between "proper" and "common" nouns, where each would contain a contrastive feature, [proper] and [common] respectively. Massam and Ghomeshi argue that N-D movement is triggered by this semantic feature difference. So to make this parameter more specific, it would appear that nouns with the semantic feature [proper], in a language with the parameter of N-D movement allowed, will raise to $\mathrm{D}$ position to check this feature, instead of using an overt determiner.

Consider the somewhat unusual phrases:

(12) ?My Maria.

(13) ?The Maria.

(14) * The my Maria.

(15) *Rome Ancient.

Examples (12) and (13) are not strictly ungrammatical. Consider the contexts: Not that Maria, my Maria and The Maria in red, not the one in yellow. However, they are certainly awkward, while (14) and (15) are undeniably ungrammatical. It seems that in English the necessary features of the D position are able to be checked without overt movement of the proper name. Under the economy condition of procrastinate (Chomsky, 2005), this movement should only happen if absolutely necessary for convergence at PF. Otherwise it can be delayed until LF. This also supports the idea that the possessive pronoun must be an internal projection or functional category of the DP, and must not occupy the D position (refer back to Longobardi, 2008). This difference of parameter settings accounts for the raising in Italian to check features that are normally checked by a null category in English. In English, the raising of N-D will procrastinate until LF, where it is not required for PF. Thus we can define the parameter of Universal Grammar, allowing for variation within the general framework already established. Within this parameter, Italian would allow $\mathrm{D}-\mathrm{N}$ movement where an overt determiner is not already present under D, and English would not allow D-N raising at all until LF.

\section{Gender Agreement}

Another research area that is hotly being debated in the field is the case of nominal gender agreement in English (e.g. Wilschko, 2009). It is often assumed that the noun phrase is assigning gender features to the determiner - at least that would be the implication of the traditional pedagogy of languages that morphologically mark gender. Wilschko (2009) argues that these determiner features (d-features) are selected (as a parameter) for a specific language. If this is a linguistic universal, it may be assumed that a language would set its parameters to include any combination of [+/- masculine, feminine $]$ or simply [unmarked] for gender, as appears to be the case in English, with the exception of personal pronouns, but these are marked to assign the gender of the third person (e.g., his, her) and does not have a gender agreement relationship with the noun in question. Wiltschko explores these options in German, Halkomelem, and Blackfoot along with several other features, including number, case and location. She found that in all three languages there are separate morphemes for gender marked determiners. One would then expect that each language treats this agreement in a syntactically similar way, according to its parameters. However, Wiltschko's study revealed an anomaly in the feminine morphological marker of determiners in Halkomelem. The results showed that the apparent [+ masc] determiner may be freely applied to a feminine noun; however the feminine marked determiner, or [- masc] cannot ever be applied to a masculine noun. Moreover, there was no apparent difference in meaning between the masculine or feminine marked determiner with a feminine noun. This was accounted for by the idea that, since there is no neuter form, that which was assumed to be [+ masc] is actually completely unmarked. The parameters would then only include an unmarked determiner and a $[+$ fem $]$ one, and the $[+$ fem $]$ would occur only to specify the "femininity" of the noun, whereas otherwise it would be unimportant. Another complication is that the inflectional morphemes of nouns in some languages will "match" their respective determiners (be phonologically identical). Wiltschko appeals to the minimalist theory of agree (Chomsky, 1998) to account for these variations, claiming that those previously mentioned are produced or "spelled-out" earlier than those that are not similar in their morphemes.

\section{Optionality}

The last phenomenon that we will consider is that of optionality. As we have seen, in English the use of an overt determiner may be optional, and its use will change the semantic interpretation but not the grammaticality (e.g., dogs vs. the dogs). In all languages, this difference is not as apparent, as is the case for nominal syntagmatic compounds in Spanish. This is the structure of noun phrases that include prepositional complements with their respective noun phrase complements, which may or may not be headed by an overt DP. Compare the two 
structures as represented by Hǿeg Müller (2009: p. 163):

(16) Crisis de la energía. [N1 prep. def. N2]

Lit.: Crisis of the energy.

(17) Fuente de energía. [N1 prep. N2] Lit.: Fountain of energy.

To native speakers, the difference is subtle. However, since both examples exist, it is not likely that the meanings are identical as language in general avoids such ambiguity. It cannot simply be a matter of specificity, as is the largely assumed feature for all definite articles, since there are examples of generic meaning within the structure of (16) as well. Hǿeg Müller (2009) posits that the features checked with an overt determiner will semantically agree in referentiality, or a prototype meaning, whereas the lack of an overt determiner will assign either a mass reading or a concept. Referentiality will make a prototype reference, whereas specificity will denote a general or mass concept representation. This notion is consistent with the theories posited above. As for the first structure, the idea that a determiner checks a [+/- identifiable] feature is a common phenomenon. The subtle difference is then of the prototype to mass reading. A prototype is still, in semantic definition, a specific reference. Consider the following examples from Hǿeg Müller:

(18) Pulpo del melón. Lit.: Pulp of the melon.

(19) Pulpo de melón. Lit.: Pulp of melon (Melon pulp.)

In (18), the meaning is that of prototypical melon pulp. However, the relationship of melón in (19) to pulpo is that of a mass reading. It refers to melon pulp in general. In this case, the null or overt determiners and the noun melón would need to "share" syntactic features, as mentioned above. Therefore, the difference in their distribution must be inherently semantic.

Another area of concern about optionality can be seen in Old French and its seemingly random use of determiners. Bare nominals can occur as arguments, and so the determiner is not needed. Also, there are examples of bare noun arguments that can be interpreted as definite, even without a definite marker. Mattieu (2009) cites La Cantilene de Sainte Eulalie as including examples of free alteration between inclusion or exclusion of a determiner. This freedom of optionality is problematic for the theory of economy. Under the assumptions put forth by minimalism, if the determiner can be avoided, it should be. Language is efficient in this way: unnecessary elements tend to be eliminated. Mathieu argues that in this case there is "no evidence for a null determiner, since bare nouns in subject and object position does not show an asymmetry in their distribution" (p. 135). However, this is not evidence that a null category does not exist. It is merely evidence that the study of this particular language would cause a linguist to miss the necessity of the null category for a universally inclusive theory. It has been proposed that this apparent discrepancy between the absence or presence of a determiner is that the language is simply in the process of change (Carlier \& Goyens, 1998). This is true of any language given that it is constantly changing and thus, this is not a complete explanation. Mathieu also disagrees with this approach, and instead suggests that the including of a syntactically unwarranted determiner is marking focus or emphasis, which is a discourse function, or to mark a metric requirement, which is a PF function. The latter will no doubt include the internal projection or functional category NumP, where the determiner will be overtly placed. Mathieu bases his findings on the theory that Old French is a $[+$ arg, + pred] language, following the Nominal Mapping Parameter of Chiercha (1998), a classification of languages according to their allowance of bare nominals as arguments. As we have seen, it is possible in Old French to use a bare nominal as both an argument and a predicate, whereas in Italian this is not the case. So, we have added this parameter to our understanding of determiners: if the language is set to include overt determiners to mark argumentation or predication it will do so, if not, it will use determiners for some other function (e.g., "focus" as described above). Modern French, of course, has lost this [focus] feature in determiners. Mathieu claims that this is because the overt plural and case marking disappeared and so the determiner was forced to carry more functional features to make up for this loss.

\section{Focus on Gender Agreement}

Gender agreement, which we have briefly touched on above, between nouns and determiners is a sharing or feature percolation process. The noun has an inherent gender, and where the morphology of the determiner in a given language distinguishes between grammatical gender the noun will share this feature with the determiner, resulting in a grammatical utterance. In the next few sections we will consider in further detail this particular feature of DPs to provide comparable examples of work being done in this research area.

\section{Applied Linguistics: L1 Acquisition and Gender Agreement}

According to nativist theories, children acquire language in such a way that it has been compared to other aspects of life that must be learned, such as learning to walk or brushing one's teeth (Clark, 2003). When one considers the intricate aspects of language learning in general this is a remarkable feat. In fact, many adults could not overtly explain how their native language works in some aspects. Uninterpretable features (or $\varphi$ features, Chomsky, 1995), including nominal gender, are somewhat extraordinary to acquire, since they are not easy to explain and their overt phonological representation does not always follow a concrete rule. For example, in Spanish (which will be the source of all comparisons here for the sake of clarity and simplicity) the gender of the noun might be recognizable (-o would indicate [+ masculine], -a would indicate $[-$ masculine]) (Bull, 1965). This is not a well-defined rule, but rather a generalization. It is also rare that a parent would take the time to formally instruct an infant about these rules and even rarer yet that any small child would understand them. However, somehow children do acquire this feature in Spanish and in fact, they develop accuracy in this area very early in life (Liceras, Diaz, \& Monegon, 2000). In this way, the feature agreement of DPs holds interesting implications for nativist and behavourist theories (Chomsky, 1965; Skinner, 1957). For if language is entirely learned through a stimulus-response mechanism the acquisition of uninterpretable features seems unlikely. In this way, the uninterpretable features of determiners seem to favour a nativist theory in which these features and the appropriate parameters for these features would be set by the language faculty at work, as with every other aspect of language, by sorting through the input.

\section{Applied Linguistics: Child L2 Acquisition and Gender Agreement}

The area of L2 acquisition is where the question of gender 
agreement really begins to spark controversy. Gender agreement with determiners is a well-known hurdle for L2 learners (Montrul, Foote, \& Perpiñán, 2008; White, Valenzuela, Kozlowska-Macgregor, \& Leung, 2004). Liceras et al. (2000) sought to explore child L1 and L2 acquisition by comparing longitudinal data elicited from two sets of children: two L1 Spanish-speaking children (López Ornat, 1994) and two L2 Spanish-speaking children (Aguirre, 1995). The researchers analyzed gender and number agreement errors between determiners, nouns and adjectives, as well as gender agreement in occurrences of n-drop. N-drop or null nouns refer to the phenomena of dropping the noun in a determiner-noun phrase construction, and referring to the noun by only the determiner and an adjective, preposition, or complement phrase (e.g., La roja - the red (one), los del comité - the (ones) from the committee, la que viene - the (one) that is coming). In this way, the gender of the noun is integral to the semantic interpretation. To exemplify this, imagine that two friends are visiting a clothing store and one friend wants to know which piece of clothing the other friend likes. While standing at a rack of clothing containing a red shirt (camisa roja-fem.) and a red dress (vestido rojo-masc.), one friend asks the other friend, "cuál te gusta más?"-which (one) do you like better?" When the friend who answers replies, "la roja" (the-fem. red-fem (one)), this can only refer to the camisa because it is the feminine noun and thus cannot refer to a vestido (i.e., this would posit the LF “*la-fem. vestido-masc. rojas-fem."). Even if the reader does not speak Spanish, this is an obvious error. The determiner and adjective must agree with the gender and number of the noun, even if that noun is implied. These examples demonstrate that the gender of the determiner plays a semantic role that otherwise would have been arbitrary.

In Liceras et al. (2000), which examines gender agreement in nominal phrases produced by L1 and L2 children speakers of Spanish, the results suggested that the native Spanish speaking children acquired n-drop agreement long before acquiring overt noun agreement (gender and number errors seem to disappear around the age of $2 ; 5$, and n-drop is produced accurately at ages $1 ; 10$ and $1 ; 11$ ). Although this is a syntactic anomaly, assuming that the syntactic determiner feature agreement assigns the morphology in both n-drop and overt noun expressions, it could be proposed that a semantic licencing condition is at work in this instance to merit the extra attention to null noun agreement. Gender and number agreement are accurate only when it is essential for comprehension.

\section{Applied Linguistics: Adult L2 Acquisition and Gender Agreement}

In considering adults in L2 acquisition of gender, one wonders whether or not this feature parameter is even acquirable? Or is there evidence that this is not a universal feature, but a particular setting specific to every language, even languages that have the concept of nominal gender in common?

Bruhn de Garavito and White (2002) looked at a group of French L2 learners of Spanish (low proficiency and low-intermediate proficiency) participated in an elicited responses task (Lightbown, 1983) in which they were required to describe pictures to an experimenter. A series of three picture options were presented, and the participants, who were university beginner Spanish students and native speakers of French, chose one picture to describe. The noun phrases produced were analysed for gender and number accuracy. These results were compared to those of Lightbrown (1983), which examined students with a first language that does not have a nominal gender feature (specifically English L2 learners of French). Their hypothesis was that if gender if transferable as a syntactic feature, the French L1 speakers should be able to transfer this feature over to their L2 (Spanish). However, the results of the two groups were comparable, indicating that gender is at least not a transferable feature, even if activated in the L1 (French learners of Spanish). This begs the question, is it acquirable? A mountain of proficient L2 learners would suggest that it is, but some linguists continue to argue that it is not (e.g. Franceschina, 2005).

\section{Lingering Question 1: Transfer Hypothesis}

Upon careful observation of Liceras et al. (2000) and Bruhn de Garavito and White (2002), two major issues still remain. One is that they provide evidence for transfer theories. Three main theories that are affected by this area of research are the Full Access Hypothesis (Epstein, Flynn, \& Martohardjono, 1996), the Full Transfer/Full Access Hypothesis (Schwartz \& Sprouse, 1996; White, 1985), and the Missing Surface Inflection Hypothesis (Prévost \& White, 2000), and each theory in its own right has compelling evidence in different fields of study. The evidence of gender agreement in determiner-noun constructions seems to provide support for the Missing Surface Inflection Hypothesis. This is, however, not definitive evidence for one theory as a whole over another, but provides evidence that at least in this aspect, nominal gender agreement seems to favour a theory that allows for acquisition of proper features and features strength (as supported in Liceras et al. in which L2 child learners of Spanish developed n-drop agreement before overt noun agreement), but where "learners sometimes have a problem with realization of surface morphology" (Prévost \& White, 2000: p. 110).

\section{Lingering Question 2: Default Hypothesis}

The second major question concerns the notion that the masculine determiner is almost always used as a "default" in L2 learners (or their respective interlanguage). This means that almost all errors that occur will be a masculine determiner with a feminine noun, and not likely a feminine determiner with a masculine noun. This had lead researchers to propose that the masculine determiner acts as a "default" until the features are fully acquired. However, White et al. (2004) point out the error in simply accepting this phenomenon without question:

This preference for one gender over another clearly requires explanation. [...] If there is a breakdown in feature checking but no loss of gender on nouns, one would anticipate problems in both directions (p. 128).

Remarkably, this controversy has provided evidence for a more lexical approach to syntax, namely distributed morphology (Halle \& Marantz, 2003). In this theory, there is only one feature, that of $[+\mathrm{fem}]$, and the masculine determiner is unmarked or underspecified for gender (Prévost \& White, 2000). Under this assumption, using a masculine determiner with a feminine noun is not a feature clash, but rather a noun with gender features and a determiner without. The default determiner wins a sort of competition between morphology options, and although it is not the best option available, it appears to be the easiest in some sense. 


\section{Applied Linguistics: Psycholinguistics and Gender Agreement}

Psycholinguistics has recently provided affective and fruitful results in areas of research that have strong implications for theoretical linguistics. Mental representations of words and how these words are processed in the context of cross-linguistic competition caused by bilingualism have led to models of lexical access and inhibition (Green, 1986, 1998; Schwieter \& Sunderman, 2008, 2009). However, if the above questions are to be answered, perhaps it would be more helpful to include what we know from psycholinguistics. In terms of transfer theories, evidence from studies concerning gender agreement seem to lend support to a "partial/full access" theory, involving access to a system of universal grammar (see "Applied Linguistics: Adult L2 Acquisition and Gender Agreement" Section). However, the default theories have yet to be explained, as this phenomenon has only been noticed and hypothesised. The inhibition of the feminine determiner (which has theoretically been acquired but perhaps is not being produced) would make an interesting study, if applied to already well-known theories of lexical inhibition. Schwieter and Sunderman's (2008) Selection by Proficiency Model addresses the issue of language selection and control in speakers of more than one language. It essentially theoretically explains how the bilingual mind is able to select the language in which to speak and choose the words to verbalize. The connection that can be drawn to functional morphology also involves the idea of inhibition. The overuse of the masculine singular determiner in Spanish (el, un) in place of the feminine (la, una), which is often dismissed as a default but not explained, could be addressed with a similar theory of inhibition. If both morphemes are acquired, and one is syntactically superior to the other but inexplicably supressed to favor the other, perhaps extending theories of inhibition to include functional morphology within a single language in L2 learners could help unravel the questions concerning why this pattern occurs?

\section{Summary}

The above evidence for DP structure in English and universal syntactic theory opens a base for research in the acquisition of this functional category. Some evidence from the study of English DPs has provided valuable insight into syntactic theory, but a truly universal theory that has the ability to accommodate every language is merited. To come to this, various aspects, including feature parameters, must be adjusted. When these theories are applied to real world languages, such as in L1 and L2 acquisition, there has been some debate over how this category actually performs. The errors that occur are particularly interesting, and go far beyond the one common error in a single language. The implication for how this area is acquired as an L1 (behaviourist vs. nativist theories), as well as how it is acquired as an L2 (transfer hypothesis and default hypothesis) is enormous, and requires further investigation. These future studies would additionally benefit greatly from the cooperation of other areas of linguistics showing evidential progress, including psycholinguistics.

\section{REFERENCES}

Abney, S. (1987). The English noun phrase in its sentential aspect. Ph.D. Dissertation, Cambridge, MA: Massachusetts Institute of Technology (MIT).
Aguirre, C. (1995). The acquisition of functional categories in Spanish. Unpublished Doctoral Dissertation, Madrid: Universidad Autónoma de Madrid.

Brame, M. (1981). The general theory of binding and fusion. Linguistic Analysis, 7, 277-325.

Brame, M. (1982). The head selector theory of lexical specifications and the non-existence of coarse categories. Linguistic Analysis, 10, 321-325.

Bruhn de Garavito, J., \& White, L. (2002). L2 acquisition of Spanish DPs: The status of grammatical features. In A. T. Pérez-Leroux, \& J. M. Liceras (Eds.), The acquisition of Spanish morphosyntax: The L1/L2 connection (pp. 151-176). Dordrecht: Kluwer.

Bull, W. (1965). Spanish for teachers: Applied linguistics. New York: The Ronald Press Co.

Carlier, A., \& Goyens, M. (1988). From Old French to New French: Regression of zero degree determination and restructuring system. Cahiers de L'Institut Linguistique de Louvain, 24, 77-112. http://dx.doi.org/10.2143/CILL.24.3.2002591

Carnie, A. (2002). Syntax: A generative introduction. Malden, MA: Blackwell Publishers.

Chomsky, N. (1965). Aspects of the theory of syntax. Cambridge, MA: MIT Press.

Chomsky, N. (1995). The minimalist program. Cambridge, MA: MIT Press.

Chomsky, N. (1998). Minimalist inquiries. MIT Occasional Papers in Linguistics, Cambridge, MA: Massachusetts Institute of Technology.

Clark, E. V. (2003). First language acquisition. Cambridge: Cambridge University Press.

Cowper, E., \& Currie Hall, D. (2009). Argumenthood, pronouns, and nominal feature geometry. In J. Ghomeshi, I. Paul, \& M. Wiltschko (Eds), Determiners: Universals and variations (pp. 97-122). Amsterdam: John Benjamins Publishing Company.

Epstein, S., Flynn, S., \& Martohardjono, G. (1996). Second language acquisition: Theoretical and experimental issues in contemporary research. Brain and Behavioral Sciences, 19, 677-758. http://dx.doi.org/10.1017/S0140525X00043521

Franceschina, F. (2005). Fossilized second language grammars: The acquisition of grammatical gender. Amsterdam: John Benjamins Publishing Company.

Gillon, C. (2009). The semantic core of determiners: Evidence from Skwxwu7mesh. In J. Ghomeshi, I. Paul, \& M. Wiltschko (Eds.), Determiners: Universals and variations (pp. 177-214). Amsterdam: John Benjamins Publishing Company.

Ghomeshi, J., \& Massam, D. (2009). The proper D connection. In J. Ghomeshi, I. Paul, \& M. Wiltschko (Eds.), Determiners: Universals and variations (pp. 67-98). Amsterdam: John Benjamins Publishing Company.

Green, D. (1986). Control, activation, and resource: A framework and a model for the control of speech in bilinguals. Brain and Language, 27, 210-223. http://dx.doi.org/10.1016/0093-934X(86)90016-7

Green, D. (1998). Mental control of the bilingual lexico-semantic system. Bilingualism: Language and Cognition, 1, 67-81. http://dx.doi.org/10.1017/S1366728998000133

Halle, M., \& Marantz, A. (1993). Distributed Morphology and the Pieces of Inflection. In: K. Hale, \& S. Jay Keyser, (Eds.), The view from building 20 (pp. 111-176). Cambridge, MA: MIT Press.

Hǿeg Müller, H., \& Klinge, A. (2008). Introduction. In: H. Hǿeg Müller, \& A. Klinge (Eds), Essays on nominal determination (pp. 163-188). Amsterdam: John Benjamins Publishing Company.

Korzen, I. (2008). Determination in endocentric and exocentric languages. In H. Hǿeg Müller, \& A. Klinge (Eds.), Essays on nominal determination (pp. 79-100). Amsterdam: John Benjamins Publishing Company.

Lightbown, P. (1983). Exploring relationships between developmental and instructional sequences in L2 acquisition. In: H. Seliger, \& M. Long (Eds.), Classroom-oriented research in second language acquisition (pp. 217-243). Rowley, MA: Newbury House.

Liceras, J., Diaz, L., \& Monegon, C. (2000). N-drop and determiners in native and non-native Spanish: More on the role of morphology in the acquisition of syntactic knowledge. In R. P. Leow, \& C. Sanz (Eds.), Current research on the acquisition of Spanish (pp. 67-96). 


\section{G. KLASSEN, J. W. SCHWIETER}

Somerville, MA: Cascadilla Press.

Longobardi, G. (1994). Reference and proper names: A theory of $\mathrm{N}$ movement in syntax and logical form. Linguistic Theory, 25, 609665.

Longobardi, G. (2008). Reference to the individuals, person and the variety of mapping parameters. In: H. Hǿeg Müller, \& A. Klinge (Eds.), Essays on nominal determination (pp. 189-212). Amsterdam: John Benjamins Publishing Company.

López Ornat, S. (1994). The acquisition of the Spanish language. Madrid: Siglo XXI.

Mathieu, E. (2009). From local blocking to cyclic agree. In: J. Ghomeshi, I. Paul, \& M. Wiltschko (Eds.), Determiners: Universals and variations (pp. 123-158). Amsterdam: John Benjamins Publishing Company.

Montrul, S., Foote R., \& Perpiñán, S. (2008). Gender agreement in adult second language learners and Spanish heritage speakers: The effects of age and context of acquisition. Language Learning, 58, 503-553. http://dx.doi.org/10.1111/j.1467-9922.2008.00449.x

Postal, P. M. (1966). A note on "understood intransitively". International Journal of American Linguistics, 32, 90-93. http://dx.doi.org/10.1086/464886

Prévost, P., \& White, L. (2000). Missing surface inflection or impairment in second language acquisition? Evidence from tense and agreement. Second Language Research, 16, 110-133.

Skinner, B. F. (1957). Verbal behavior. New York: Appleton-CenturyCrofts. http://dx.doi.org/10.1037/11256-000
Schwartz, B., \& Sprouse, R. (1996). L2 cognitive states and the full transfer/full access hypothesis. Second Language Research, 12, 4072. http://dx.doi.org/10.1177/026765839601200103

Schwieter, J. W., \& Sunderman, G. (2008). Language switching in bilingual speech production: In search of the language-specific selection mechanism. The Mental Lexicon, 3, 214-238. http://dx.doi.org/10.1075/ml.3.2.06sch

Schwieter, J. W., \& Sunderman, G. (2009). Concept selection and developmental effects in bilingual speech production. Language Learning, 59, 897-927.

http://dx.doi.org/10.1111/j.1467-9922.2009.00529.x

White, L. (1985). The "pro-drop" parameter in adult second language learning. Language Learning, 35, 47-62. http://dx.doi.org/10.1111/j.1467-1770.1985.tb01014.x

White, L., Valenzuela, E., Kozlowska-Macgregor, M., \& Leung, Y. (2004). Gender and number agreement in nonnative Spanish. Applied Psycholinguistics, 25, 105-133. http://dx.doi.org/10.1017/S0142716404001067

Wiltschko, M. (2009). What's in a determiner and how did it get there? In J. Ghomeshi, I. Paul, \& M. Wiltschko (Eds.), Determiners: Universals and variations (pp. 25-66). Amsterdam: John Benjamins Publishing Company.

Zamparelli, R. (2008). Bare predicate nominals in romance languages. In: H. Hǿeg Müller, \& A. Klinge (Eds.), Essays on nominal determination (pp. 101-130). Amsterdam: John Benjamins Publishing Company. 